\title{
Towards soil compaction limits for crop growth
}

\author{
F. R. Boone
}

Department of Soil Tillage, Agricultural University, Diedenweg 20, 6703 GW Wageningen, Netherlands

\section{Problem and challenge}

In modern agriculture soil structure is under increasing stress by a combination of different causes. Diminishing financial profits stimulated narrow rotations of intensive crops in heavily mechanized cropping systems. For optimal utilization of the growing season sowing and planting occurs as early as possible and harvest is late in the season, both increasing the risks of substantial damage to soil structure. Seedbed and plant-bed preparation carried out as soon as soil trafficability is sufficient and the soil is workable only until sowing depth, results in a considerably compacted soil beneath seed-bed depth. If wheel tracks are distributed haphazardly over the field a large part of the field gets the same soil density as before the main tillage operation after the harvest of the previous crop. This has been already recognized several decades ago (Kuipers, 1963; Håkansson, 1965). Meanwhile farm equipment has become larger and the cropping systems have become more intensive. A recent survey in a marine clay district in the Netherlands (van de Zande, 1983) reveals that also nowadays only a small part of the field remains untouched by wheels whereas the greater part is affected more than once, even up to eight times.

Harvest operations of cash crops like potatoes and sugar-beet under unfavourable soil conditions affect soil structure negatively sometimes even below the arable layer. Although this only sporadically may happen the negative effects may have long-lasting effects. Repair of soil structure below the usually tilled layer is under discussion but often is considered to be short-lasting if the mechanization system is not adapted concurrently (Kooistra et al., 1984). Another example of soil structure under stress is found on sandy soils with mixed farming, covering roughly $50 \%$ of the Netherlands, where maize for silage has become a major crop. The number of cows and pigs has increased strongly and reached the level where there is now not enough land to absorb the manure. The exorbitant heavy traffic involved in spreading as much manure as possible and for as long as possible in winter and early spring compacts the soil to considerable depths and tillage and sowing maize must be concentrated in a very short period of time.

In this context there is a remarkable analogy in relation to present-day industrial society. The past century, and especially the past 50 years, has been dedicated to technical expansion and improvement of technologically profitable processes. The same occurred in agriculture with respect to fertilization, mechanization and the choice of cropping systems. Secondary effects on the environment such as industrial 


\section{F. R. BOONE}

pollution and degradation of soils used for agriculture, of which soil compaction is an essential part, was recognized only the past decade. A common feature is accumulation of the effects in time, with some effects becoming clear only after a considerable period of time. Sometimes these effects can be removed only at high costs which cannot be paid by normal exploitation. In agriculture a well-known example is soil erosion. Mechanical damage of soil in vulnerable situations might be a potential hazard. It is not too theoretical that soil structure of an unstable soil can be destroyed to a depth of $1 \mathrm{~m}$ by mismanagement and might need biannual deep loosening if that management is continued.

The existance of threshold values of soil structure has been indicated by various types of research. The most well-known is research in no-tillage or direct-drilling where the soil is compacted by field traffic but never loosened. Compared to a normal tilled soil many aspects are changed, but for certain crops and situations, undoubtedly excessive soil compaction is the main aspect responsible for the observed yield losses (Cannell, 1985). These findings are supported by research in which soil structure is the only parameter changed (Soane, 1985). The empirical results from these experiments, however, cannot be easily extrapolated from one situation to another. In the future a more thorough knowledge of the relation between soil compaction and crop growth is necessary in order to make a more efficient use of applied energy and chemicals. If farmers are primarily machine-minded and not soil (structure) minded, problems with crops and soils certainly will arise automatically. In order to be able to optimize soil physical fertility for maximum crop growth it is of utmost importance that easily applicable criteria for soil structure will be found. Only in that case it is possible to avoid future problems and reverse them into advantageous situations by introducing an active soil structure policy. Below presentday knowledge will be indicated, some of the white spots at the interface of applied soil physics and crop science mentioned and a new approach introduced.

\section{Common relationships between soil compaction and crop growth}

In contrast to what is generally believed, viz that soil compaction depresses crop yield, four clearly different types of reaction are mentioned in literature. For instance, in areas where no-tillage is applied successfully with proper management no statistically significant relation between soil compaction and yield is found (Allmaras \& Dowdy, 1985). The second type of response is that yield increases due to compaction (Darcey et al., 1984). In many cases this is caused by improved plant establishment and not by improved crop growth. The third possibility, that yields decrease by compaction, is commonly cited and this is also of considerable economic importance because beyond a certain degree of compaction, crop responses to small increments of soil density are quite often severe. These three possible responses to soil density are contradictory at first sight. However, from research covering the whole range of soil densities which can be established for a certain soil, it appears that these different responses are segments of an optimum curve (Eriksson et al., 1974; Fig. 1). This optimum curve is not unique, but shape and position greatly depend on a number of factors. Generally speaking this optimum is shifting to a 


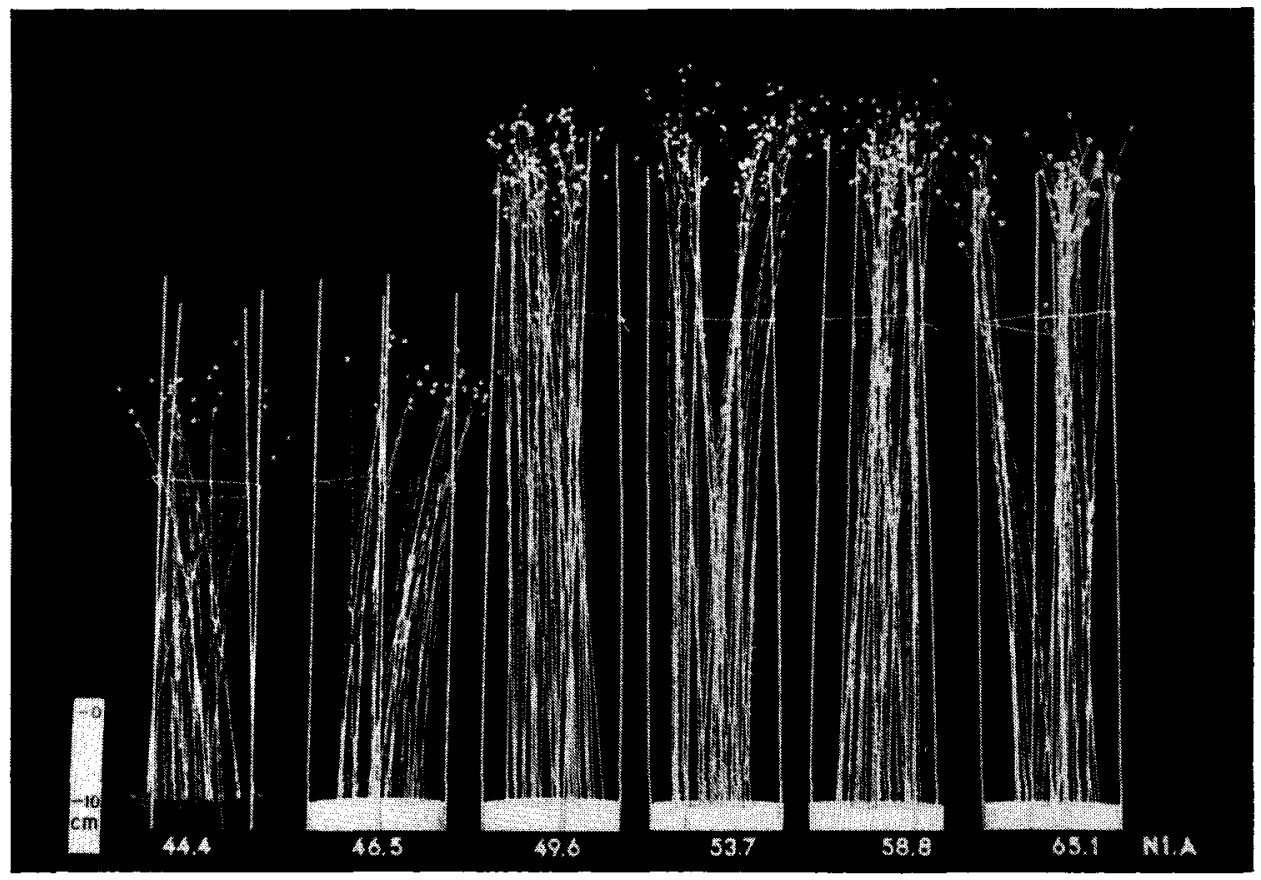

Fig. 1. Relationship between growth of flax at constant water supply and total soil porosity as indicated by figures (F. R. Boone, unpublished pot experiment).

soil with a lower density when soil texture is fine instead of coarse, when wet instead of dry soil is compacted, when dicotyledons instead of monocotyledons are grown and when the soil is wetter during the growing season. The last aspect means that in areas with large climatic variations between growing seasons the response curves will vary considerably.

The basic reason for a yield response to soil compaction is that the supply of water and/or ions has been smaller than the crop demands. The higher the crop demands the higher the supply should be. In principle, the range of optimum production will be smaller the higher the yield is. The fact that various factors modify the general response curve support the conclusion that no single soil structure related factor can be used as the determinating factor for all situations. Specific air contents (Boekel, 1963) or penetration resistances (Taylor \& Gardner, 1963) have proven to be valuable emperical tools in specific experiments but are invalidated for general application by numerous other experiments under different experimental conditions (e.g. Ehlers et al., 1983; Boone et al., 1984). The reason no universal factor is found up till now can be explained by considering the complex system of functional relationships between soil compaction and crop growth (Fig. 2). 


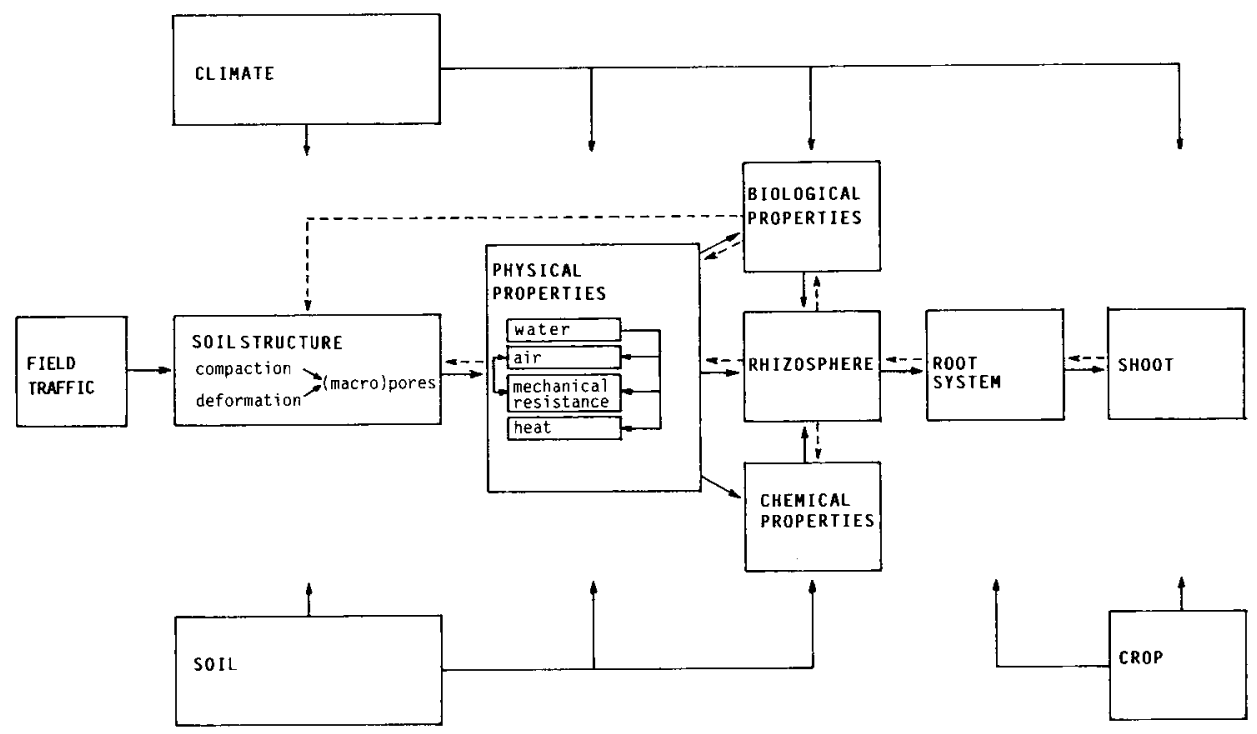

Fig. 2. Simplified scheme of functional relationships between soil compaction and crop growth.

\section{Functional relationships between soil compaction and crop growth}

\section{Soil compaction - soil structure}

In establishing criteria for soil structure with respect to crop growth it is crucial to understand and be able to predict the processes which occur at compaction. Initial soil structure and conditions in combination with the stresses applied at compaction determine the final result. Studies on soil compactibility generally start from the solid soil constituents and focuss on changes in soil structure on a macro-scale. A complication in compaction research is that compaction as measured by volume changes and deformation of the soil matrix with structural rearrangements at constant volume occur together (Koolen, 1986).

For crop growth changes on a micro-scale and especially changes in the pore system are studied. In this respect the insight is growing that soil deformation which strongly depends on soil moisture, plays an important or even dominating role in compaction under wet conditions (Kuipers, 1985). Obviously the larger the applied stresses are and the wetter the soil is, the less important the soil structure at the start of the compaction is. In less extreme situations the arrangement and the compactibility-deformability characteristics of the aggregates will play a role which may be decisive in situations that are nearly critical for plant growth.

Systematic research in this field in relation to changes in the pore system has not been undertaken up till now. This may be partly due to methodological problems. Some micromorphological characteristics of the pore system can be measured very 
well with thin sections but are not applicable on a large-scale basis. A very important aspect of soil compaction is that the largest pores gradually disappear (Sommer et al., 1972; Boone et al., 1985). Indirect physical methods which are available for measuring the pore size distribution are used frequently but are not appropriate for the largest macropores and the results are biased by hysteresis. Characteristics of the pore system which are even more important such as the continuity and direction of the pores and their spatial variability, however, are even more cumbersome to measure quantitatively.

Several decades ago it has been recognized that changes in soil spatial variability is probably the most essential aspect of soil tillage and field traffic on soil structure (Kuipers, 1963). When soil structure is defined as the spatial arrangement and binding of the solid soil particles it automatically includes a scale aspect. In recent years much work is devoted to the consequences of such structural patterns on the movement of water (Bouma \& Raats, 1985). At the same time spatial variability in a general sense and applied on a much larger, soil survey, scale has drawn much attention and led to the adoption of geostatistical techniques and scaling methods (Nielsen \& Bouma, 1985). The changes by soil tillage and traffic in spatial variability on a field basis are partly intended, for example preparing a loose finely aggregated seed-bed on top of a more firm and less finely aggregated root-bed, and partly not intended, for example inducing a plough-pan or strongly compacted soil by wheel tracks. In cases with clear horizontal or vertical patterns, sampling is often adapted to the pattern and the scale of variability. Most often these patterns are not easily detectable or are too complicated and then samples are taken at random and mean values and standard deviations related to the sample size are calculated. Nonuniformity with abnormally distributed values appears to be standard and not the exception in the field (e.g. Hamblin, 1985). Moreover it has been accepted more and more than in many instances mean values are meaningless. This strengthens the need to develop a new approach in which the scale aspect of soil structure and the special function of extreme values are incorporated. These aspects are important in relation to soil physical and root system properties. The application of a grid system or variable sample sizes in combination with modern statistics needs further attention. It is clear that extreme values at the favourable end of the scale are crucial because only a small part of the soil has to have favourable characteristics for root penetration (Boone \& Kuipers, 1970).

Soil structural variability with time sometimes can be neglected but is a strongly modifying factor superimposed on the influence of soil tillage and traffic in other situations. In general it holds that the less mechanically stable the structure, the longer the time involved, the more variable weather and soil conditions, the higher the swelling and shrinking potential of the soil and the higher biologically active the soil fauna creating meso- and macro-pores, the more these factors have to be acknowledged. Even small changes in soil structure in situations nearly critical for root growth may have significant consequences. 


\section{Crop growth factors changed by soil compaction}

Changes in soil structure by compaction directly affect soil physical and indirectly chemical and biological factors. It is beyond the scope of this article to discuss these relations. Instead, a few recent developments and results will be noted and comments will be given.

Water, air, mechanical impedance and heat are soil physical factors which can be substantially altered by soil compaction. Important facets are changes in soil surface properties and capacity and transmission characteristics. The significance of each of these changes largely depend on the actual situation in combination with the absolute value of the factor under consideration and the magnitude of the change.

Dynamic aspects of situations. A decrease in saturated hydraulic conductivity of, for instance, 100 down to $10 \mathrm{~mm} \mathrm{h-1} \mathrm{may} \mathrm{be} \mathrm{insignificant} \mathrm{in} \mathrm{a} \mathrm{temperate} \mathrm{climate} \mathrm{on}$ a flat land but may cause runoff on rolling land or during tropical rain. Especially with soil surface properties a single, static value will not suffice and has to be supplemented by a stability factor, for example against rain drop impact. Soil physical conditions also develop with time by interaction with environmental factors. Moreover a situation which is disadvantageous at one moment may be advantageous at another or vice versa. Severe compaction of a subsoil on a marine loam resulted in temporary accumulation of water in the ploughed top-soil in winter which accelerated reconsolidation of the ploughed soil (Boone et al., 1978). However, the compacted subsoil significantly increased capillary rise from the groundwater which substantially promoted early potato growth during a dry spell (van Loon et al., 1978).

Coincidence of circumstances. In the Netherlands, winter wheat direct-drilled on a very dense marine loam soil untilled for several years survives well, even during winters with much rain (van Ouwerkerk \& Lumkes, 1984). When winter wheat is sown in finely crumbled soil resulting from potato harvesting on top of the same untilled soil, the seed-bed severely slaked in winters with much rain. On horizontal, flat parts of the field most plants still survived but in micro-depressions of only a few centimetres, many plants died by water ponding. This problem was solved in subsequent years by mixing the finely crumbled soil with some coarser aggregates by superficially cultivating the soil. This example is typical for many field situations and makes clear that critical situations often occur by a coincidence of several near-critical factors. This is a major complication in defining critical values for single factors.

Effect of layers. Root and shoot growth start near the soil surface and the main direction of root growth as well as the exchange of water, gases and heat is vertical. This has several consequences in respect to the effect of place and dimensions of a layer with unfavourable characteristics. In the first place even a thin layer may have harmful effects if it creates a bottleneck in vertical direction and if moreover the dimensions in the horizontal direction are (much) larger than the dimensions of the root system. The deeper a layer in the soil profile, the larger the buffering capacity 
of the overlying soil and the smaller the risks of harmful effects to the crop. On the other hand, however, a deeper layer will leave the crop less time to pass or gradually disrupt such a barrier. In situations where, for instance, water stress occurs late in the season, the consequence of an unfavourable layer relatively deep in the profile may be still considerable. The total effect of any, more or less temporary, obstruction can be quantified in such situations by integrating the differences between potential crop demands and actual supply functions during the total growing season. Nevertheless research all over the world has proven that soil structure above sowing or planting depth is of special interest. The preparation of a (shallow) seed-bed is the last what is abandoned in cropping systems aiming at a minimum soil loosening. Even successful modern direct-drilling equipment establishes some kind of a seed-bed directly around the seed (Baker \& Mai, 1982).

Duration of effects. Various soil physical growth factors, of which a few specific facets related to soil compaction have been mentioned, also affect chemical and biological aspects of the soil system. For example, the soil in the field is compacted in less than one second increasing the risk for water logging which may induce denitrification for days or even weeks. Most biological and chemical effects have a still longer duration and the establishment of a new equilibrium in, for instance, the organic matter and nitrogen balance is not to be expected within years (Titulaer \& Boone, 1984). Short-term effects may dominate but the final judgement on a tillage and traffic system has to be made over several crop rotations integrating all positive and negative aspects (Lumkes et al., 1984).

Main effects at different phases of compaction. Various factors are simultaneously altered by compaction and have to be discussed separately as well as in combination because some of them show major interactions. When a soil of loosely packed aggregates is compacted step by step it is supposed that the following schematic sequence occurs. In the first phase of compaction, the saturated hydraulic conductivity of the soil is still high and the unsaturated hydraulic conductivity still low, the gas exchange capacity still high but the heat exchange capacity and the mechanical impedance for roots still low. Water infiltrates rapidly but the surface will dry out fast because capillary rise is slow. This may hamper seed germination and emergence especially when the seed is placed close to the surface. A higher plant density is one of the reasons that yield increases by slight compaction of very loose soil. Root growth rate is high because roots can grow easily in the large pores which still exist between the aggregates. The functioning of the root system, however, may be suboptimal because the root-soil contact (de Willigen \& van Noordwijk, 1984) and the hydraulic conductivity of the soil surrounding the root are still relatively small. In compaction phase two these resistances for water flow and intake are decreased to such an extent that the supply function is equal to or higher than the actual crop requirement. The other functions mentioned diminish but still meet crop requirements which means that in this phase of compaction there will be no crop response. In the next phase one or another factor will become suboptimal while others still will meet the requirements. 


\section{F. R. BOONE}

It can be imagined that in any phase of compaction, the weakest spots in the soil are compacted. These spots with the highest concentration of large macro-pores or weakest aggregates then become stronger until other unchanged spots will be weaker. Compaction then changes to these spots and the total soil volume gradually becomes more resistant to compaction. Spatial variability of soil structure diminishes. The largest macro-pores collapse especially at the weakest spots where pore necks are originated. Because water flow in circular pores depends on the fourth power and gas diffusion on the second power of the radius of these pore necks, saturated hydraulic conductivity hampered even more strongly than the exchange of gases. At an increasing number of spots aggregates cluster and behave as larger units in which center oxygen concentration decreases. Consequently the number and volume of potentially anaerobic spots increases. The pore necks also diminish the number of mechanically easily rootable spots which affects thick roots first. Root growth is slowed down considerably even by a small external pressure which has not a physical but a physiological reason (Goss \& Russell, 1980). As long as the ratio between the number of easily rootable places and the number of roots is high the root system is only affected slightly morphologically and its functioning may be even improved by an enhanced unsaturated hydraulic conductivity of the soil and an improved soil-root contact.

A concept of critical soil density. The effects mentioned above are becoming more pronounced at further compaction. The requirement of the crop and the supply of the root-soil system of a specific growth factor will be in balance at a certain phase of compaction. This can be regarded as the critical soil density for that factor (Boone et al., 1986) because at further compaction this growth factor is becoming suboptimal and crop growth will be hampered. Which growth factor is becoming suboptimal first depends on a complex of soil, location, climatic and crop factors. In this complex water plays a central role as a very important growth factor with important interactions with all other growth factors affected by soil compaction. Soil structural requirements are least in situations with a constant supply of water during the whole growing season. Plants are then adapted as well as possible and make maximum use of the prevailing situation. The more soil water conditions change in time the more variable soil growth factors and the higher the demands on soil structure. At further compaction more factors may become suboptimal. In such situations yield reductions are considerable.

The concept of critical soil density has been applied on compaction of sandy soils in Dutch temperate climatic conditions. In these experiments on flat fields even the most severe compaction applied before shallow seed-bed preparation and sowing of maize did not impose infiltration or runoff problems. Soil water potentials during early crop growth also were very similar. Influences of compaction on soil temperature were supposed to be negligible because the seed-bed was loose in all treatments. Therefore only soil aeration and mechanical impedance had be to dealt with. A potentially good soil structure should guarantee at least sufficient root growth and function between field capacity and wilting point. From the combination of water retention curves and gas diffusion coefficients, determined at several 


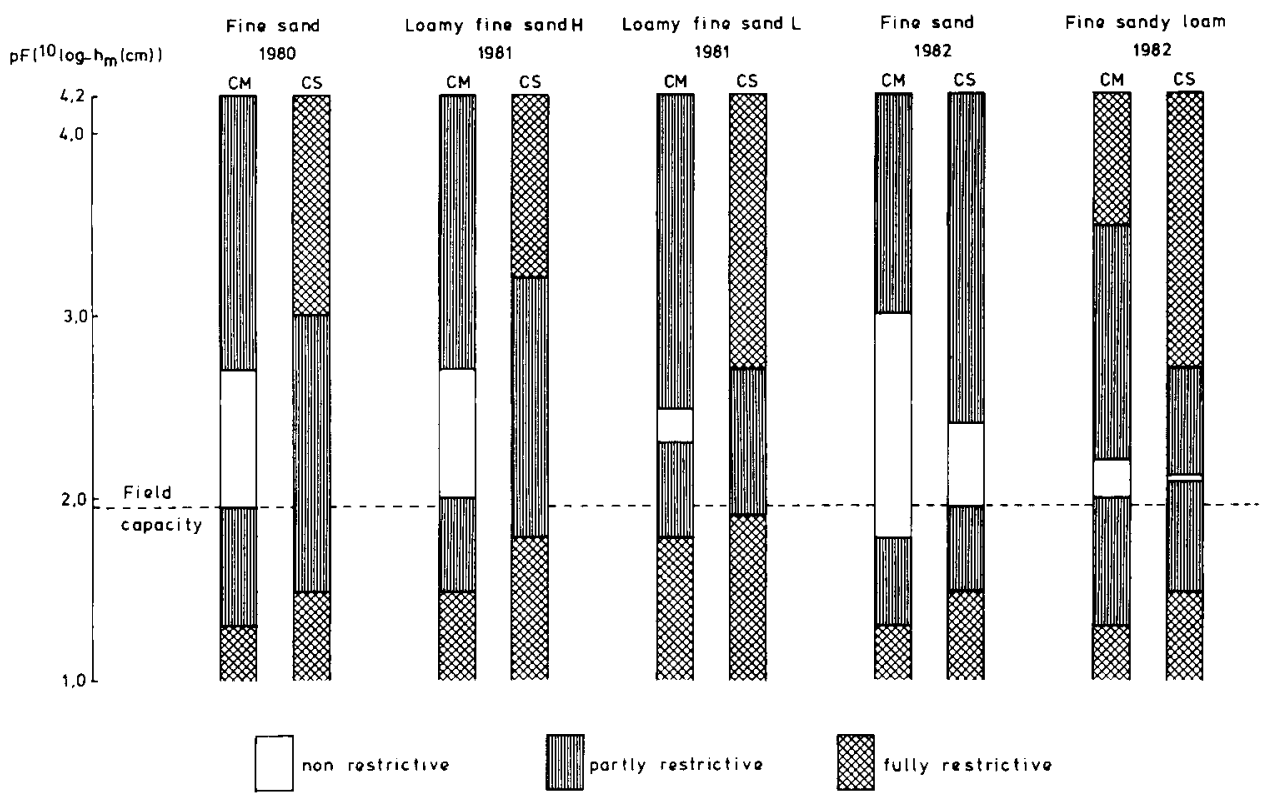

Fig. 3. Range of non-restrictive, partly and fully restrictive matric water potentials of moderately (CM) and severely (CS) compacted arable layers in sandy soils based on gas diffusion coefficients and penetration resistances (Boone et al., 1986).

soil water potentials, and the assumption of certain aeration limits, the critical soil water potential at the wet side was determined for each compaction treatment. The arable layer was at field capacity at sowing and therefore the soil density that corresponded with a soil water potential equal to field capacity could be considered as critical. The higher the critical soil water potential (wetter soil), the larger the buffering capacity with respect to aeration during wet periods. For the mechanical impedance a similar procedure was followed with other parameters. For both indices a distinction was made between unimpeded, partly impeded and totally impeded root growth (Fig. 3). The larger the range of soil water potentials which enable unimpeded or partly impeded root growth the better the prospects for maximum crop growth. In future the chances and duration that certain soil water potentials are exceeded in given sets of conditions should be translated in risks of yield losses.

\section{Towards a soil structure index}

Soil tillage research indicates that threshold soil density values quite often are closely reached in practice (Boone et al., 1986; Fig. 4). This implies that only a small change in the conditions or the system applied will increase the risk of inducing yield depressions. Present-day yields in most cases are below theoretically obtainable levels and it should be doubted if in a number of cases soil structure is sufficient for maximum yields. It is to be expected that the mechanical stress applied on 


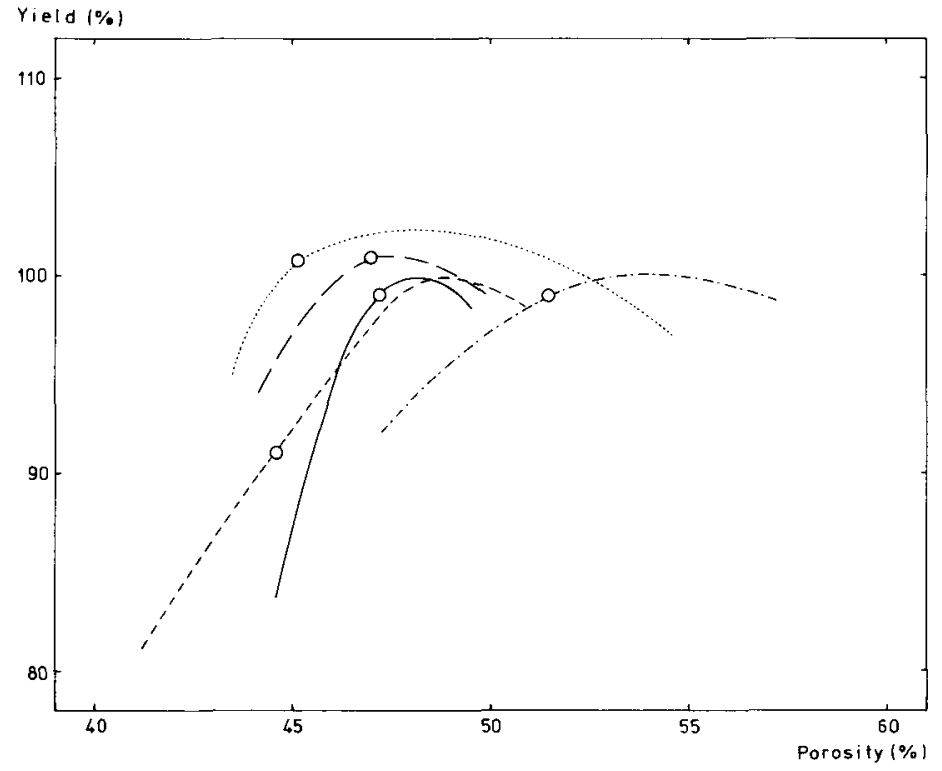

Fig. 4. Relative yields of maize for silage in various experiments in the Netherlands as a function of total porosity in the arable layer of sandy soils. The porosity obtained by driving once all over the soil after ploughing with a $44 \mathrm{~kW}$ tractor with double rear wheels before seed-bed preparation, as sometimes practised, is indicated by a circle (F. R. Boone et al., in preparation).

soil still will increase in future and it is necessary to develop limits of acceptance. It is a challenge to detect and predict which soil structures will have a higher than quantified acceptable risk. The concept of critical soil density therefore should be developed further. Special attention should be paid to the circumstances at compaction (soil structure, soil conditions and forces applied) and the assessment of a soil structure/spatial variability index which includes rootability and root function aspects. Ultimately these parameters should be transduced and reduced to a simple soil structure index which can be used in agricultural practice on a small, field basis. There appears to be an increasing request for such a structure index (Soane \& Boone, 1986).

\section{References}

Allmaras, R. R. \& R. H. Dowdy, 1985. Conservation tillage systems and their adoption in the United States. Soil and Tillage Research 5: 197-222.

Baker, C. J. \& T. V. Mai, 1982. Physical effects of direct drilling equipment on undisturbed soils. 5. Groove compaction and seedling root development. New Zealand Journal of Agricultural Research 25: 51-60.

Boekel, P., 1963. Soil structure and plant growth. Netherlands Journal of Agricultural Science 11: 120127.

Boone, F. R. \& H. Kuipers, 1970. Remarks on soil structure in relation to zero-tillage. Netherlands Journal of Agricultural Science 18: 262-269. 
Boone, F. R., J. Bouma \& L. A. H. de Smet, 1978. A case study on the effect of soil compaction on potato growth in a loamy sand soil. 1. Physical measurements and rooting patterns. Netherlands Journal of Agricultural Science 26: 405-420.

Boone, F. R., B. Kroesbergen \& A. Boers, 1984. Soil conditions and growth of spring barley on a tilled and untilled marine loam soil. In: F. R. Boone (Ed.), Experiments with three tillage systems on a marine loam soil. II: 1976-1979, p. 124-166. Agricultural Research Reports 925. Pudoc, Wageningen.

Boone, F. R., L. A. H. de Smet \& C. D. van Loon, 1985. The effect of a ploughpan in marine loam soils on potato growth. 1. Physical properties and rooting patterns. Potato Research 28: 295-314.

Boone, F. R., H. M. G. van der Werf, B. Kroesbergen, B. A. ten Hag \& A. Boers, 1986. The effect of compaction of the arable layer in sandy soils on the growth of maize for silage. 1. Critical matric water potentials in relation to soil aeration and mechanical impedance. Netherlands Journal of Agricultural Science 34: 139-156.

Bouma, J. \& P. A. C. Raats (Eds.), 1985. Proceedings of the ISSS symposium on water and solute management in heavy clay soils. ILRI, (Wageningen) Publication No 37.

Cannell, R. Q., 1985. Reduced tillage in North-West Europe. A review. Soil and Tillage Research 5: 129-177.

Darcey, C. L., L. H. Wilkes \& K. E. Watkins, 1984. Elevated lane for controlled wheel traffic. ASAE Paper No 84-1539. ASAE, St. Joseph, MI 49085, USA.

Ehlers, W. , U. Köpke, F. Hesse \& W. Böhm, 1983. Penetration resistance and root growth of oats in tilled and untilled loess soil. Soil and Tillage Research 3: 261-275.

Eriksson, J., I. Håkansson \& B. Danfors, 1974. Effect of soil compaction on soil structure and crop yields. Swedish Institute of Agricultural Engineering Bulletin 544, $101 \mathrm{pp}$.

Goss, M. J. \& R. S. Russell, 1980. Effects of mechanical impedance on root growth in barley (Hordeum vulgare L.). III. Observations on the mechanism of response. Journal of Experimental Botany 31: 577588.

Håkansson, I., 1965. Some soil structural aspects of modern farm management. Grundförbättring 18: 89-98.

Hamblin, A. P., 1985. The influence of soil structure on water movement, crop root growth and water uptake. In: Advances in Agronomy 38: 95-158. Academic Press, New York.

Kooistra, M. J., J. Bouma, O. H. Boersma \& A. Jager, 1984. Physical and morphological characterization of undisturbed and disturbed ploughpans in a sandy loam soil. Soil and Tillage Research 4: 405417.

Koolen, A. J., 1986. Behaviour of elemental soil volumes in compaction and effects on properties of significance in soil use. Proceedings ISSS Conference (August 1986, Hamburg).

Kuipers, H. \& C. van Ouwerkerk, 1963. Total pore-space estimations in freshly ploughed soil. Netherlands Journal of Agricultural Science 11(1): 45-53.

Kuipers, H., 1984. The challenge of soil cultivations and soil water problems. Journal of Agricultural Engineering Research 29(3): 177-190.

Loon, C. D. van \& J. Bouma, 1978. A case study on the effect of soil compaction on potato growth in a loamy sand soil. 2. Potato plant responses. Netherlands Journal of Agricultural Science 26: 421-429.

Lumkes, L. M., F. R. Boone, C. van Ouwerkerk \& W. A. P. Bakermans, 1984. General conclusions. In: F. R. Boone (Ed.), Experiences with three tillage systems on a marine loam soil. II. 1976-1979, p. 257-261. Agricultural Research Reports 925. Pudoc, Wageningen.

Nielsen, D. R. \& J. Bouma (Eds.), 1985. Soil spatial variability. Proceedings of a workshop of the ISSS and the SSSA (Las Vegas, 1984). Pudoc, Wageningen.

Ouwerkerk, C. van \& L. M. Lumkes, 1984. Crop response. In: F. R. Boone (Ed.), Experiences with three tillage systems on a marine loam soil. II. 1976-1979, p. 89-123. Agricultural Research Reports 925. Pudoc, Wageningen.

Soane, B. D., 1985. Traction and transport systems as related to cropping systems. Proceedings International Conference on Soil Dynamics (June, 1985, Auburn, Alabama, USA): 863-935.

Soane, B. D. \& F. R. Boone, 1986. The effects of tillage and traffic on soil structure. Report on Workshop Discussion 2. 10th Conference International Soil Tillage Research Organization (July 1985, Guelph, Canada). Soil and Tillage Research (in press).

Sommer, C., K. Stoinev \& H. J. Altemüller, 1972. Das Verhalten vier verschiedener Modelböden unter vertikaler Belastung. Landbauforschung Völkenrode 22(1): 45-56. 


\section{F. R. BOONE}

Taylor, H. M. \& H. R. Gardner, 1963. Penetration of cotton seedling taproots as influenced by bulk density, moisture content and strength of soil. Soil Science 96(3): 153-156.

Titulaer, H. H. H. \& F. R. Boone, 1984. Aspects of chemical soil fertility. In: F. R. Boone (Ed.), Experiences with three tillage systems on a marine loam soil. II. 1976-1979, p. 58-71. Agricultural Research Reports 925 . Pudoc, Wageningen..

Willigen, P. de \& M. van Noordwijk, 1984. Mathematical models on diffusion of oxygen to and within plant roots, with special emphasis on effects of soil-root contact. I. Derivation of the models. II. Applications. Plant and Soil: $215-231$ and 233-241.

Zande, J. C. van de, 1983. Traffic and compaction of arable land in the western part of Zuid-Beveland. Nota 1462, ICW, Wageningen, $56 \mathrm{pp}$. 